\title{
Exploring the Potential of Breast Microbiota as Biomarker for Breast Cancer and Therapeutic Response
}

\author{
Sabine Dieleman, ${ }^{{ }^{\dagger}}$ Romy Aarnoutse, ${ }^{{ }^{\dagger}}$ Janine Ziemons, ${ }^{* \dagger}$ Loes Kooreman, ${ }^{* \dagger}$ Annemarie Boleij, ${ }^{\S}$ and Marjolein Smidt ${ }^{* \dagger}$ \\ From the GROW-School for Oncology and Developmental Biology, * and the Departments of Surgery ${ }^{\dagger}$ and Pathology, ${ }^{\ddagger}$ Maastricht University Medical \\ Center+, Maastricht; and the Department of Pathology, ${ }^{\S}$ Radboud University Medical Center, Radboud Institute for Molecular Life Sciences (RIMLS), \\ Nijmegen, the Netherlands
}

Accepted for publication February 17, 2021.

Address correspondence to Marjolein Smidt, M.D. Ph.D., Maastricht University Medical Center+, 6202 AZ Maastricht, the Netherlands. E-mail: m.smidt@ mumc.nl.

\begin{abstract}
Breast cancer tissue contains its own unique microbiota. Emerging preclinical data indicates that breast microbiota dysbiosis contributes to breast cancer initiation and progression. Furthermore, the breast microbiota may be a promising biomarker for treatment selection and prognosis. Differences in breast microbiota composition have been found between breast cancer subtypes and disease severities that may contribute to immunosuppression, enabling tumor cells to evade immune destruction. Interactions between breast microbiota, gut microbiota, and immune system are proposed, all forming potential targets to increase therapeutic efficacy. In addition, because the gut microbiota affects the host immune system and systemic availability of estrogen and bile acids known to influence tumor biology, gut microbiota modulation could be used to manipulate breast microbiota composition. Identifying breast and gut microbial compositions that respond positively to certain anticancer therapeutics could significantly reduce cancer burden. Additional research is needed to unravel the complexity of breast microbiota functioning and its interactions with the gut and the immune system. In this review, developments in the understanding of breast microbiota and its interaction with the immune system and the gut microbiota are discussed. Furthermore, the biomarker potential of breast microbiota is evaluated in conjunction with possible strategies to target microbiota in order to improve breast cancer treatment. (Am J Pathol 2021, 191: 968-982; https://doi.org/10.1016/j.ajpath.2021.02.020)
\end{abstract}

Breast cancer is a heterogeneous malignancy, accounting for $30 \%$ of all female cancers. ${ }^{1,2}$ Molecular subtypes of breast cancer have been characterized, including luminal A, luminal $\mathrm{B}, H E R 2$-enriched, and triple negative breast cancer (TNBC). ${ }^{3}$ Luminal A subtype is enriched with the estrogen receptor (ER), and has the best clinical prognosis among all intrinsic subtypes, which is mostly due to the favorable response to endocrine therapy. Compared with luminal A cancers, luminal B cancers show lower expression of $E R$ related genes, but have higher expression of proliferationrelated genes and variable expression of HER2-related genes. ${ }^{4}$ The HER 2 subtype comprises approximately $15 \%$ of all invasive breast cancers and are more aggressive in nature than luminal-like cancers. ${ }^{4}$ This subtype is associated with the absence of ER and progesterone receptor (PR) expression, and overexpression of HER2/HER2 signalingassociated genes and genes located in HER2 amplicon on chromosome 17q12. TNBC lacks expression of ER, PR, and HER2.

Segregating breast tumors into subtypes is valuable for predicting prognosis and guiding clinical decision-making, in which an array of anticancer therapeutics, including chemotherapy, antiestrogen therapy, and anti-HER2targeted agents can be selected. ${ }^{5}$ Nevertheless, limitations in traditional subtyping exist, since it does not take interactions with the tumor microenvironment (TME) into account. Healthy tissue stroma normally acts as a physiological barrier against tumor formation. ${ }^{6}$ During development of neoplastic

Disclosures: None declared. 
cells, the adjacent tissue microenvironment is transformed by autocrine and paracrine mechanisms of cancer cells to maintain optimal conditions for tumor survival and progression. These alterations result in tumor-associated stroma, known as the TME. The TME consists of a heterogeneous collection of fibroblasts, myofibroblasts, neuroendocrine cells, adipocytes, extracellular matrix, blood and lymphatic vascular networks, and is enriched with many immune and inflammatory cells. ${ }^{6}$

Recent findings demonstrate the existence of microbiota, both in healthy stroma and in the TME of extraintestinal organs, including the lung, pancreas, and breast. ${ }^{7-9}$ It is suggested that organ-specific microbiota play a role in tumor development and therapeutic resistance. In this review, microbial compositions in tumorous and healthy breast tissue are discussed. Moreover, microbiota interactions with the immune system, the gut microbiota and anticancer therapeutics are illustrated. Lastly, the biomarker potential of breast microbiota is evaluated in conjunction with possible strategies to target microbiota in order to improve breast cancer treatment.

\section{Breast Microbiota in Health and Disease}

Many extraintestinal tissues were traditionally considered sterile until the advancement of culture-independent DNA sequencing techniques, using next-generation sequencing technology. ${ }^{10}$ The discovered link between colon cancer and certain gut bacteria led to novel investigations of organspecific microbiota in the development of cancers in multiple tissues. ${ }^{11}$ The existence of microbes in breast tissue was firstly demonstrated in 2014 by Xuan et al. ${ }^{8}$ There is increasing evidence of the existence of a unique microbiota in breast tissue that is distinct from the overlying breast skin, and is unrelated to mastitis. ${ }^{12}$ The breast microbiota is dominated by the phyla Proteobacteria and Firmicutes, which likely can be attributed to the fatty acid-rich environment in the breast. The discovery of microbiota in breast tissue has brought the attention to its potential role in the pathophysiological process of breast carcinogenesis.

\section{Difference between Healthy and Tumorous Breast Tissue}

Several studies have examined normal breast tissue adjacent to the breast tumor, approximately $5 \mathrm{~cm}$ away from the tumor margin. One study found a higher bacterial load and bacterial richness in breast tumor tissue, compared with adjacent normal breast tissue. ${ }^{13}$ At the phylum level, highest presence of Proteobacteria was found in breast cancer tissue, compared with highest presence of Actinobacteria in adjacent normal breast tissue. ${ }^{14}$ The families Pseudomonadaceae, Sphingomonadaceae, Alcaligenaceae, Ruminococcaceae, and Clostridia seemed to be decreased in adjacent breast tissue compared with breast cancer tissue. ${ }^{8,15,16}$ At the class level, the absolute abundance in breast tumor tissue was highest for the classes Clostridia and Bacteroidia, ${ }^{15}$ whereas at the genera level, Ralstonia, followed by Methylobacterium and Sphingomonas, had the highest abundance. ${ }^{15,17}$ In normal adjacent breast tissue, the family Enterobacteriaceae, of which Escherichia coli is a member, was increased compared with healthy controls. ${ }^{18}$ E. coli isolates, cultured from normal adjacent tissue of breast cancer patients, induced DNA double-stranded breaks in vitro in HeLa cells. ${ }^{18}$ Similarly, pks-positive E. coli bacteria induced DNA damage in human intestinal organoids by the production of the genotoxin colibactin. ${ }^{19}$ This finding provides an explanation for a possible pathway by which bacteria, present in the breast, may contribute to breast carcinogenesis.

The microbiota composition of breast tissue adjacent to the tumor has also been compared with healthy breast tissue of women without breast cancer. Compared with healthy breast tissue, adjacent normal breast tissue contained a higher relative abundance of bacteria belonging to the phylum Bacteroidetes, the family Comamondaceae, and the genera Bacillus and Staphylococcus, ${ }^{18}$ which could also suggest a gradual change in microbiota from healthy to cancerous states. However, not all studies identified differences between breast tumor tissue microbiota and adjacent normal breast tissue microbiota. ${ }^{16-18}$ Similar microbiota in paired normal tissue and tumor tissue could suggest a predisposition of the entire breast tissue to carcinogenesis and thereby potentially predict breast cancer risk.

\section{Microbiota Composition in Malignant versus Benign Breast Diseases}

The breast microbiota composition of malignant disease, mainly invasive ductal carcinoma, can clearly be distinguished from that of benign breast disease, including fibroadenoma, intraductal papilloma, and atypical hyperplasia. ${ }^{20}$ Phylum Proteobacteria, families Micrococcaceae, Caulobacteraceae, Rhodobacteraceae, Nocordioidaceae, and Methylobacteriaceae, and genus Propionicimonas were present in significantly higher levels in malignant breast cancer than in benign breast disease. ${ }^{20}$ In another study investigating breast tissue of women with $\mathrm{ER}^{+}$breast cancer, increased abundance of specific genera, including Fusobacterium, Atopobium, Hydrogenophaga, Gluconacetobacter, and Lactobaccilus, was demonstrated in invasive breast cancer compared with benign disease. ${ }^{12}$

Different stages of breast cancer also coincide with a specific microbial profile. Higher stages were associated with reduced bacterial load. ${ }^{8}$ In Stage I breast cancer, Proteobacteria, Ruminococcaceae, and Hyphomicrobium were most abundant, whereas Stage II breast cancer showed highest abundance in Euryarchaeota, Firmicutes, Spirochaetes, and the genus Sporosarcina. ${ }^{15}$ Stage III and Stage IV breast cancer exhibited elevation in Thermi, Gemmatimonadetes, and Tenericutes, and higher abundance of Bosea. The genus Agrococcus was progressively enriched with increased malignancy. ${ }^{20}$ 
Table 1 Overview of Studies Analyzing Breast Microbiota Composition

\begin{tabular}{|c|c|c|c|c|c|}
\hline Study & Sample size & Sample source & $\begin{array}{l}\text { Breast cancer } \\
\text { subtype }\end{array}$ & $\begin{array}{l}\text { Microbiota composition of } \\
\text { breast cancer tissue, } \\
\text { adjacent breast tissue, and } \\
\text { healthy breast tissue }\end{array}$ & $\begin{array}{l}\text { Microbiota composition of } \\
\text { breast cancer subtypes, } \\
\text { grades, and stages }\end{array}$ \\
\hline Banerjee et $\mathrm{al}^{21}$ & $\begin{array}{l}100 \text { triple-negative } \\
\text { breast cancer tissue } \\
\text { samples } \\
17 \text { matched (adjacent } \\
\text { breast tissue) and } 20 \\
\text { nonmatched controls }\end{array}$ & FFPE & TNBC & $\begin{array}{l}\text { Comparing TNBC tissue with } \\
\text { healthy breast tissue, } \\
\text { higher percentage of } \\
\text { probes of the genera } \\
\text { Prevotella, } \\
\text { Brevundimonas, }\end{array}$ & $\begin{array}{l}\text { In TNBC, highest prevalence } \\
\text { of probes detecting } \\
\text { Arcanobacterium (in } 75 \% \\
\text { of samples) was found, } \\
\text { followed by } \\
\text { Brevundimonas, }\end{array}$ \\
\hline
\end{tabular}

(table continues) 
Table 1 (continued)

\begin{tabular}{|c|c|c|c|c|c|}
\hline Study & Sample size & Sample source & $\begin{array}{l}\text { Breast cancer } \\
\text { subtype }\end{array}$ & $\begin{array}{l}\text { Microbiota composition of } \\
\text { breast cancer tissue, } \\
\text { adjacent breast tissue, and } \\
\text { healthy breast tissue }\end{array}$ & $\begin{array}{l}\text { Microbiota composition of } \\
\text { breast cancer subtypes, } \\
\text { grades, and stages }\end{array}$ \\
\hline & $\begin{array}{l}\text { (healthy breast } \\
\text { tissue) }\end{array}$ & & & $\begin{array}{l}\text { Arcanobacterium, } \\
\text { Escherichia, } \\
\text { Sphingobacterium, } \\
\text { Actinomyces, and Rothia } \\
\text { was found in TNBC tissue. } \\
\text { Comparing TNBC tissue with } \\
\text { healthy breast tissue, } \\
\text { higher percentage of } \\
\text { probes of the viruses } \\
\text { MMTV, hepatitis C1, } \\
\text { EBV1, BPSV, HCMV, KSHV, } \\
\text { PCPV, HPV2, HTLV-2, } \\
\text { HPV6B, MCPV, HTLV1, } \\
\text { HPV18, hepatitis B, SV40, } \\
\text { HPV16, HHV1, okra } \\
\text { mosaic virus, FSV, } \\
\text { hepatitis GB, viroids, and } \\
\text { orf virus was found in } \\
\text { TNBC tissue. } \\
\text { Comparing TNBC tissue with } \\
\text { healthy breast tissue, } \\
\text { higher percentage of } \\
\text { probes of the fungi } \\
\text { Pleistophora and } \\
\text { Paecilomyces was found } \\
\text { in TNBC tissue. }\end{array}$ & $\begin{array}{l}\text { Sphingobacteria, } \\
\text { Providencia, Prevotella, } \\
\text { Brucela, Escherichia, } \\
\text { Actinomyces, Mobiluncus, } \\
\text { Propiniobacteria, } \\
\text { Geobacillus, Rothia, } \\
\text { Peptinophilus, and } \\
\text { Capnocytophaga. } \\
\text { The highest hybridization } \\
\text { signal in TNBC was found } \\
\text { for the bacterial probe of } \\
\text { Prevotella, for the viral } \\
\text { probe of Herpesvirus, for } \\
\text { the fungal probe of Piedra, } \\
\text { and for the parasitic probe } \\
\text { of Trichuris. }\end{array}$ \\
\hline Wang et $\mathrm{al}^{16}$ & $\begin{array}{l}57 \text { breast cancer tissue } \\
\text { samples } \\
21 \text { healthy breast tissue } \\
\text { samples } \\
\text { Breast cancer stages: } \\
\text { Stage I: } n=22 \\
\text { Stage II: } n=30 \\
\text { Stage III: } n=5\end{array}$ & Fresh frozen & $\begin{array}{l}\mathrm{ER} / \mathrm{PR}^{+}(n=50) \\
\mathrm{HER2}^{+}(n=9)\end{array}$ & $\begin{array}{l}\text { Comparing breast cancer } \\
\text { tissue with healthy } \\
\text { breast tissue, decreased } \\
\text { relative abundance of } \\
\text { Methylobacterium and } \\
\text { increased relative } \\
\text { abundance of } \\
\text { Alcaligenaceae were } \\
\text { found in breast cancer } \\
\text { tissue. } \\
\text { Comparing breast cancer } \\
\text { tissue with adjacent } \\
\text { breast tissue, no } \\
\text { significant differences } \\
\text { were found. }\end{array}$ & $\begin{array}{l}\text { Comparing } \mathrm{HR}^{+} \text {breast } \\
\text { cancer tissue with } \mathrm{HR}^{-} \\
\text {breast cancer tissue, } \\
\text { increased Shannon } \\
\text { diversity and decreased } \\
\text { relative abundance of } \\
\text { Methylobacterium was } \\
\text { found in } \mathrm{HR}^{+} \text {breast } \\
\text { cancer. }\end{array}$ \\
\hline Thompson et $\mathrm{al}^{14}$ & $\begin{array}{l}\text { The Cancer Genome } \\
\text { Atlas (TCGA) } \\
668 \text { breast cancer tissue }\end{array}$ & Fresh frozen & $\begin{array}{l}\mathrm{ER}^{+}, \mathrm{HER}^{+}, \mathrm{TNBC} \\
\text { (distribution is } \\
\text { not given) }\end{array}$ & $\begin{array}{l}\text { In breast cancer tissue, } \\
\text { phylum Proteobacteria } \\
\text { was most abundant, }\end{array}$ & * \\
\hline
\end{tabular}

(table continues) 
Table 1 (continued)

\begin{tabular}{|c|c|c|c|}
\hline Study & Sample size & Sample source & $\begin{array}{l}\text { Breast cancer } \\
\text { subtype }\end{array}$ \\
\hline & $\begin{array}{l}\text { samples } \\
72 \text { adjacent breast } \\
\text { tissue samples }\end{array}$ & & \\
\hline Banerjee et $\mathrm{al}^{22}$ & $\begin{array}{l}148 \text { breast cancer tissue } \\
\text { samples } \\
20 \text { healthy breast tissue } \\
\text { samples }\end{array}$ & FFPE & $\begin{array}{l}\mathrm{ER} / \mathrm{PR}^{+}(n=50) \\
\mathrm{HER}^{+}(n=34) \\
\mathrm{ER}^{+} \mathrm{PR}^{+}, \mathrm{HER}^{+} \\
\quad(n=24) \\
\mathrm{TNBC}(n=40)\end{array}$ \\
\hline
\end{tabular}

Microbiota composition of breast cancer tissue, adjacent breast tissue, and healthy breast tissue

Microbiota composition of breast cancer subtypes, grades, and stages followed by

Actinobacteria and

Firmicutes.

In adjacent breast tissue, highest presence of phylum Actinobacteria was observed.

For all breast cancer subtypes, significant hybridization signals were found for Actinomyces, Bartonella, Brevundimonas, Coxiella, Mobiluncus,

Mycobacterium, Rickettsia, and Sphingomonas.

No bacterial signatures in healthy breast tissue were found of the following bacteria that were detected in breast cancer tissue:

Actinomyces, Aerococcus, Arcanobacterium, Bifigdobacterium, Bordetella,

Cardiobacterium,

Corynebacterium, Eikenella, Fusobacterium, Geobacillus, Helicobacter, Kingella, Orientia, Pasteurella,

Peptinophilus, Prevotella, Rothia, Salmonella, and Treponema.
In ER/PR ${ }^{+}$breast cancer, highest hybridization signals were found for probes of viruses Anelloviridae and Flaviviridae, and for fungal probes of Filobasidiella, Mucor, and Trichophyton.

Comparing ER/PR ${ }^{+}$breast cancer tissue with healthy breast tissue, signals for Arcanobacterium, Bifidobacterium, Cardiobacterium, Citrobacter, and Escherichia were associated with ER/ $\mathrm{PR}^{+}$breast cancer tissue.

In HER2 ${ }^{+}$breast cancer, highest hybridization signals were found for probes of the virus Togaviridae, and the fungi Epidermophyton,

Fonsecaea, and Pseudallescheria.

The virus Nodoviridae was only detected in HER2 ${ }^{+}$ breast cancer.

In $\mathrm{ER} / \mathrm{PR}^{+}, \mathrm{HER}^{+}{ }^{+}$breast cancer, highest hybridization signals were found for probes of the virus Polyomaviridae and the fungus Penicillum.

Comparing ER/PR ${ }^{+}, \mathrm{HER}^{+}$ breast cancer tissue with healthy breast tissue, signals for Bordetella, Campylobacter, Chlamydia, Chlamydophila, Legionella, and Pasteurella were associated with ER/PR ${ }^{+}$, HER2 ${ }^{+}$breast cancer.

In TNBC, highest hybridization signals were found for probes of viruses Picornaviridae and Anelloviridae, and fungi Alternaria, Malassezia,

(table continues) 
Table 1 (continued)

\begin{tabular}{|c|c|c|c|c|c|}
\hline Study & Sample size & Sample source & $\begin{array}{l}\text { Breast cancer } \\
\text { subtype }\end{array}$ & $\begin{array}{l}\text { Microbiota composition of } \\
\text { breast cancer tissue, } \\
\text { adjacent breast tissue, and } \\
\text { healthy breast tissue }\end{array}$ & $\begin{array}{l}\text { Microbiota composition of } \\
\text { breast cancer subtypes, } \\
\text { grades, and stages }\end{array}$ \\
\hline
\end{tabular}

Sample source subtype Sample size

grades, and stages

Piedraia, and Rhizomucor.

Comparing TNBC tissue with healthy breast tissue, signals for Aerococcus, Arcobacter, Geobacillus, Orientia, and Rothia were associated with TNBC tissue.

\begin{tabular}{|c|c|}
\hline Meng et $\mathrm{al}^{20}$ & $\begin{array}{l}94 \text { breast tumor tissue } \\
\text { samples: } \\
22 \text { benign breast } \\
\text { tumors; } 72 \text { malignant } \\
\text { breast cancer (grade } \\
\text { I: } n=7, \text { grade II: } \\
\begin{array}{l}n=36, \text { grade III: } \\
n=13, \text { N0-grade: } \\
n=16 \text { ) }\end{array}\end{array}$ \\
\hline
\end{tabular}

Fresh frozen

$\mathrm{ER}^{+}(n=47)$

ER- $(n=25)$

2 benign breast

breast cancer (grade

I: $n=7$, grade II:

$n=13$, N0-grade:

Smith et $\mathrm{al}^{15}$

$$
\begin{aligned}
& 53 \text { breast cancer tissue } \\
& \text { samples } \\
& 11 \text { adjacent breast } \\
& \text { tissue samples } \\
& 8 \text { healthy breast tissue } \\
& \text { samples } \\
& \text { Breast cancer stage: } \\
& \text { Stage I: } n=13 \\
& \text { Stage II: } n=24 \\
& \text { Stage III and IV: } \\
& n=19 \\
& \text { Missing: } n=8 \\
& \text { Non-Hispanic whites: } \\
& n=51 \\
& \text { Non-Hispanic blacks: } \\
& n=12
\end{aligned}
$$

Fresh frozen

Luminal A

$$
(n=22)
$$

Luminal B

$$
(n=14)
$$

HER2 $^{+}(n=6)$

TNBC $(n=15)$

Missing $(n=7)$
Comparing malignant

breast cancer tissue with

benign breast tumor

tissue, increased relative

abundance of

Proteobacteria,

Micrococcaceae,

Caulobacteraceae,

Rhodobacteraceae,

Nocordioidaceae,

Methylobacteriaceae, and

Propionicimonas was

found in malignant

breast cancer tissue.

Comparing healthy breast

tissue with breast cancer

tissue, higher alpha

diversity, decreased

relative abundance of

Pseudomonadaceae,

Sphingomonadaceae, and

Ruminococcaceae, and

increased relative

abundance of

Actinomycetaceae were

found in healthy breast tissue.

Comparing adjacent breast tissue to breast cancer tissue, lower relative abundance of

Ruminococcaceae and Clostridia was found in adjacent breast tissue.

Comparing adjacent breast tissue with healthy breast tissue, higher relative abundance of

Pseudomonadaceae was found in adjacent breast tissue.

In breast cancer tissue, class Clostridia, Bacteroidia, and family Ruminococcaceae were found to be most abundant. Family Xanthomonadaceae was
Comparing grade III breast cancer tissue with grade I and II breast cancer tissue, higher alpha diversity was found in grade III breast cancer. With increasing grade, decreased relative abundance of Bacteroidaceae and increased relative abundance of Agrococcus were found.

In luminal $\mathrm{A}$ breast cancer, order Xanthomonadales was most abundant.

In luminal B breast cancer, genus Clostridium was most abundant.

In the luminal subtypes, phyla Tenericutes, Proteobacteria, and Planctomycetes were most abundant.

In $\mathrm{HER}^{+}{ }^{+}$breast cancer, genus Akkermansia and phyla Thermia and Verrucomicrobia were most abundant.

In TNBC, genera Streptococcaceae and Ruminococcus, and phyla Euryarchaeota, Cyanobacteria, and Firmicutes were most abundant.

In Stage I breast cancer, family Ruminococcaceae, and genus Hyphomicrobium were most abundant.

In Stage II breast cancer, genus Sporosarcina was most abundant.

In Stage III and IV breast cancer, genus Bosea was most abundant.

(table continues) 
Table 1 (continued)

\begin{tabular}{|c|c|c|c|c|c|}
\hline Study & Sample size & Sample source & $\begin{array}{l}\text { Breast cancer } \\
\text { subtype }\end{array}$ & $\begin{array}{l}\text { Microbiota composition of } \\
\text { breast cancer tissue, } \\
\text { adjacent breast tissue, and } \\
\text { healthy breast tissue }\end{array}$ & $\begin{array}{l}\text { Microbiota composition of } \\
\text { breast cancer subtypes, } \\
\text { grades, and stages }\end{array}$ \\
\hline Costantini et $\mathrm{al}^{17}$ & $\begin{array}{l}16 \text { breast cancer tissue } \\
\text { samples } \\
16 \text { adjacent breast } \\
\text { tissue samples }\end{array}$ & Fresh tissue & $\begin{array}{l}\mathrm{ER}^{2} \mathrm{PR}^{+}(n=14) \\
\mathrm{ER}^{-} \mathrm{PR}^{-}(n=2) \\
\mathrm{HER}^{+}(n=1) \\
\mathrm{HER}^{-}(n=15) \\
\operatorname{TNBC}^{-}(n=1)\end{array}$ & $\begin{array}{l}\text { most abundant in breast } \\
\text { cancer tissue of non- } \\
\text { Hispanic white women. } \\
\text { Genus Ralstonia was most } \\
\text { abundant in breast } \\
\text { cancer tissue of non- } \\
\text { Hispanic black women. } \\
\text { Families } \\
\text { Pseudomonadaceae, } \\
\text { Sphingomonadaceae, and } \\
\text { Caulobacteraceae were } \\
\text { most abundant in } \\
\text { adjacent breast tissue. } \\
\text { In breast cancer tissue, } \\
\text { phylum Proteobacteria } \\
\text { was most abundant, } \\
\text { followed by Firmicutes, } \\
\text { Actinobacteria, and } \\
\text { Bacteroidetes. } \\
50 \% \text { to } 75 \% \text { of relative } \\
\text { abundances belonged to } \\
\text { genera Ralstonia, } \\
\text { Methylobacterium, and } \\
\text { Sphingomonas. } \\
25 \% \text { to } 50 \% \text { of relative } \\
\text { abundances belonged to } \\
\text { genera Staphylococcus } \\
\text { and Pseudomonas, and to } \\
\text { families } \\
\text { Bradyrhizobiaceae and } \\
\text { Rhodocyclaceae. } \\
\text { Comparing breast cancer } \\
\text { tissue with adjacent } \\
\text { breast tissue, no } \\
\text { significant differences } \\
\text { were found. }\end{array}$ & * \\
\hline Nejman et $\mathrm{al}^{13}$ & $\begin{array}{l}355 \text { breast cancer tissue } \\
\text { samples } \\
173 \text { adjacent breast } \\
\text { tissue samples } \\
54 \text { healthy breast tissue } \\
\text { samples }\end{array}$ & $\begin{array}{l}\text { Fresh frozen and } \\
\text { FFPE (majority } \\
\text { of samples) }\end{array}$ & $\begin{array}{l}\mathrm{ER}^{+}, \mathrm{PR}^{+}, \mathrm{HER}^{+} \\
\quad \text { (distribution is } \\
\text { not given) }\end{array}$ & $\begin{array}{l}\text { In breast cancer tissue, } \\
9190 \text { bacterial species } \\
\text { were detected in total. } \\
\text { Breast tumors had a richer } \\
\text { and more diverse } \\
\text { microbiome than other } \\
\text { tumors (melanoma, lung, } \\
\text { ovary, bone, and } \\
\text { glioblastoma multiforme } \\
\text { tumors). } \\
\text { Comparing breast cancer } \\
\text { tissue with adjacent } \\
\text { breast tissue and healthy } \\
\text { breast tissue, higher } \\
\text { bacterial load and } \\
\text { richness were found in } \\
\text { breast cancer tissue. }\end{array}$ & $\begin{array}{l}\text { Differences in microbiota } \\
\text { composition were found } \\
\text { between breast cancer } \\
\text { subtypes, based on ER, PR, } \\
\text { and HER2 expression. } \\
\text { Most enriched pathways in } \\
\text { bacteria within ER }{ }^{+} \text {breast } \\
\text { cancer tissue were } \\
\text { arsenate detoxification } \\
\text { and mycothiol } \\
\text { biosynthesis. }\end{array}$ \\
\hline
\end{tabular}

*Not described or investigated in the study.

FFPE, formalin-fixed paraffin-embedded; TNBC, triple-negative breast cancer. 


\section{Breast Microbiome in Breast Cancer Subtypes}

Remarkably, the breast tumor subtypes luminal A, luminal B, TNBC, and HER2 ${ }^{+}$were found to exhibit unique subtypeassociated microbiota. ${ }^{13,15,21,22}$ Luminal A tumor tissue exhibited highest abundance of order Xanthomonadales, and luminal B tumor tissue showed highest abundance of the genus Clostridium. ${ }^{15}$ In most hormone-positive breast cancer tissues, the genus Methylobacterium had a decreased presence compared with that in healthy breast tissue. ${ }^{16}$ In HER2 tumors, Akkermansia was most abundant. ${ }^{15}$ TNBC tissue was shown to harbor Streptococcaceae and Ruminococcus at the highest level in one study. ${ }^{15}$ In another study, using the PathoChip array, a higher percentage of Prevotella, Brevundimonas, Arcanobacterium, Escherichia, Sphingobacterium, Actinomyces, and Rothia was found in TNBC tissue compared with healthy breast tissue. ${ }^{21}$

All these studies show considerable heterogeneity in microbiota composition of healthy breast, normal adjacent, and tumorous breast microbiota. It seems clear that a breast microbiome exists and that it may change during the course of breast cancer development. However, a clear breast cancer microbiota profile has not been defined yet. This could be due to several reasons: i) the low microbial biomass in the breast organ, which increases the risk of contamination influencing the results; ii) small sample sizes; and iii) the variety of extraction and sequencing methods used. Understanding microbial differences and their role in carcinogenesis will be important to estimate breast cancer risk from a microbiome perspective. In Table 1, studies evaluating breast microbiota composition are chronologically listed in detail. In Table 2, the breast microbiota compositions of various breast cancer subtypes can be found.

\section{Immune Involvement in Breast Carcinogenesis}

The immune system plays a significant role in the initiation, progression, and control of cancer. This is illustrated by the process of cancer immunoediting, which describes the evolving interactions between host immunity and cancer cells, consisting of three distinct phases: elimination, equilibrium, and escape. ${ }^{23}$ In the elimination phase, tumor cells are successfully recognized and eliminated by immune cells. During equilibrium, transformed cells escape elimination and are able to proliferate. However, this proliferation is still controlled by the immune system, in contrast to the escape phase, which is defined by uncontrolled proliferation. In a healthy situation, a balance exists between proinflammatory and anti-inflammatory signals, which is partly regulated by costimulation and coinhibition of $\mathrm{T}$ cells. ${ }^{24}$ This enables sufficient clearance of foreign antigens, but concurrently prevents uncontrolled inflammation. Tumors are able to avoid immune destruction by several mechanisms, including loss of antigenicity and recruitment of immunosuppressive leukocytes. $^{25}$

\section{Immunosuppression in Breast Tumor Tissue}

Breast cancer is characterized by infiltrated immune cells in the tumor tissue, where immunosuppressive cells are dominant over proinflammatory cells. High magnitude of tumor-infiltrating lymphocytes in the breast is associated with better prognosis and therapeutic response in certain breast cancer subtypes. ${ }^{26}$ Lymphocytes exhibiting antitumor activity include $\mathrm{CD}^{+}$cytotoxic $\mathrm{T}$ lymphocytes, which eliminate cancer cells, and $\mathrm{CD}^{+}{ }^{+} \mathrm{T}$ helper 1 lymphocytes, which activate cytotoxic T lymphocytes. ${ }^{27} \mathrm{In} \mathrm{ER}^{+} \mathrm{HER}^{+}$ tumors, presence of tumor-infiltrating cytotoxic $\left(\mathrm{CD}^{+}\right) \mathrm{T}$ cells was associated with a $27 \%$ reduction in the hazard of dying from breast cancer. ${ }^{28}$

It is hypothesized that tumors recruit immunosuppressive cells in order to evade immune destruction. ${ }^{28}$ Repressors of $\mathrm{T}$ cells, such as myeloid-derived suppressor cells and $\mathrm{T}$ regulatory cells, are found in higher numbers in patients with breast cancer compared with healthy controls, and increase with tumor stage. $^{29,30}$ Tumor-associated macrophages, which resemble the anti-inflammatory M2-polarized macrophages, promote tumor growth by secretion of antiinflammatory cytokines, such as IL-10 and transforming growth factor- $\beta .^{31,32}$ High infiltration of tumor-associated macrophages in breast tissue is associated with malignancy, negative hormone receptor status, and poor diseasefree and overall survival. ${ }^{33}$

\section{Communication between the Immune System and Microbiota}

The innate immune system is trained in recognizing microbes via pattern recognition receptors (PRRs) that bind to bacterial components, known as pathogen-associated molecular patterns. ${ }^{34}$ Examples of PRRs include Toll-like receptors (TLRs), nucleotide-binding oligomerization domain (NOD)-like receptors, and C-type lectin receptors, which are expressed by cells such as macrophages, dendritic cells, and natural killer (NK) cells. ${ }^{34}$ TLRs induce an inflammatory response in reaction to binding with microbial structures such as lipopolysaccharide, peptidoglycan, flagella, or microbial DNA or RNA. ${ }^{35}$ Activation of TLRs can either have tumor promoting or inhibiting effects, depending on the TLR subset, cancer type, and involved immune cells in the tumor. ${ }^{36}$ In breast carcinomas of mice xenografts, TLR5 was found to be highly expressed. ${ }^{37}$ In vivo administration of Salmonella typhimurium flagellin, a ligand of TLR5, stimulated secretion of proinflammatory cytokines and chemokines, mediating antitumor activity. $^{37}$ In another study, lipopolysaccharide/TLR4 signaling resulted in a protumorigenic effect by up-regulating production of IL-6 and IL-10. ${ }^{38}$ These observations might explain the importance of breast microbiota in breast cancer, because certain microbial components recognized by PRRs in the breast can induce a tumor-inhibiting inflammatory response, contributing to recruitment of tumor-killing cells. 
Table 2 Microbiota Composition of Breast Cancer Subtypes

\begin{tabular}{|c|c|c|}
\hline Study & $\begin{array}{l}\text { Breast cancer } \\
\text { subtype } \\
\text { definition }\end{array}$ & Microbiota composition of breast cancer subtype \\
\hline Xuan et $\mathrm{al}^{8}{ }^{8}$ Smith et $\mathrm{al}^{15}{ }^{15}$ Banerjee et $\mathrm{al}^{22}$ & $\mathrm{HR}^{+}$ & $\begin{array}{l}\text { Comparing } \mathrm{HR}^{+} \text {breast cancer tissue to adjacent breast tissue, higher } \\
\text { relative abundance of Methylobacterium radiotolerans was found in } \\
\mathrm{HR}^{+} \text {breast cancer tissue. } \\
\text { Comparing } \mathrm{HR}^{+} \text {breast cancer tissue with healthy breast tissue, signals for } \\
\text { Arcanobacterium, Bifidobacterium, Cardiobacterium, Citrobacter, and } \\
\text { Escherichia were associated with } \mathrm{HR}^{+} \text {breast cancer tissue. } \\
\text { Absolute abundance of order Xanthomonadales and phyla Tenericutes, } \\
\text { Proteobacteria, and Planctomycetes was found highest in luminal A } \\
\text { breast cancer. } \\
\text { Absolute abundance of genus Clostridium and phyla Tenericutes, } \\
\text { Proteobacteria, and Planctomycetes was found highest in luminal B } \\
\text { breast cancer. }\end{array}$ \\
\hline Smith et $\mathrm{al}^{15}$ Banerjee et $\mathrm{al}^{21,22}$ & TNBC & $\begin{array}{l}\text { Comparing TNBC tissue with healthy breast tissue, higher signals for } \\
\text { Prevotella, Brevundimonas, Arcanobacterium, Escherichia, } \\
\text { Sphingobacterium, Actinomyces, Aerococcus, Arcobacter, Geobacillus, } \\
\text { Orientia, and Rothia were found in TNBC tissue. } \\
\text { Absolute abundance of genera Streptococcaceae and Ruminococcus, and } \\
\text { phyla Euryarchaeota, Cyanobacteria, and Firmicutes was highest in } \\
\text { TNBC. }\end{array}$ \\
\hline
\end{tabular}

TNBC, triple-negative breast cancer.

Most of our understanding regarding immune cell and tissue-specific microbiota interactions, originates from studies investigating pancreatic and lung microbiota. In a study exploring microbiota in pancreatic cancer, microbiome diversity correlated with $\mathrm{CD} 8^{+} \mathrm{T}$-cell infiltration. ${ }^{39}$ Additionally, $\mathrm{CD}^{+}$immune infiltration was associated with three genera that were most abundant in long-term survivors, including Saccharopolyspora, Pseudoxanthomonas, and Streptomyces. Interestingly, in another pancreatic cancer study, TLR2 and TLR5 ligation was found to promote pancreatic cancer and induce immunosuppression. ${ }^{40}$ Moreover, these immune-suppressive effects were absent when macrophages were deficient in TLR signaling, which suggests that immunosuppression is dependent upon TLR ligation between the tumor microbiome and immune cells. In mice, lung microbiota manipulation was demonstrated to reduce the local immunosuppressive environment. Treatment with antibiotic or probiotic aerosol, 2 weeks before melanoma cell injection, resulted in decreased bacterial load in the lung accompanied by enhanced activation of NK and T effector cells, promoting tumor immunity against lung metastases. ${ }^{41}$

In summary, correlations exist between intratumoral microbiota composition and immune cell infiltration, which indicates that an unfavorable microbiota composition may contribute to tumor immune evasion.

\section{Is Therapeutic Efficacy and Cytotoxicity Governed by Intratumoral Microbiota?}

Therapeutic resistance, which can be intrinsic or required, continues to be the limiting factor in achieving successful breast cancer treatment. Responsible determinants of drug resistance include alteration in expression or mutation of a drug target, tumor heterogeneity, reduced blood flow to the tumor, and prevention of immune evasion by the TME. ${ }^{42}$ Biomarkers to predict therapeutic sensitivity of breast tumor cells are urgently required so that therapy and dose can be adjusted accordingly. In this context, gut microorganisms have been shown to mediate toxicity and related side effects of anticancer agents. For example, the inactive $\mathrm{SN}-38 \mathrm{G}$ form of the prodrug irinotecan (CPT-11) is reactivated by intestinal bacterial $\beta$-glucuronidases into the active and toxic $\mathrm{SN}-38 .{ }^{43}$ It is proposed that breast microbiota composition influences local availability and cytotoxicity of anticancer therapeutics as well, and thus could be used as a marker to determine drug efficacy and toxicity.

Via endogenous enzymes, bacteria have the ability to transform organic compounds. ${ }^{44}$ Administration of bacteria found in breast cancer tissue, namely Gram-negative E. coli and Gram-positive Listeria welshimeri, are able to either enhance or reduce efficacy and cytotoxicity of different 


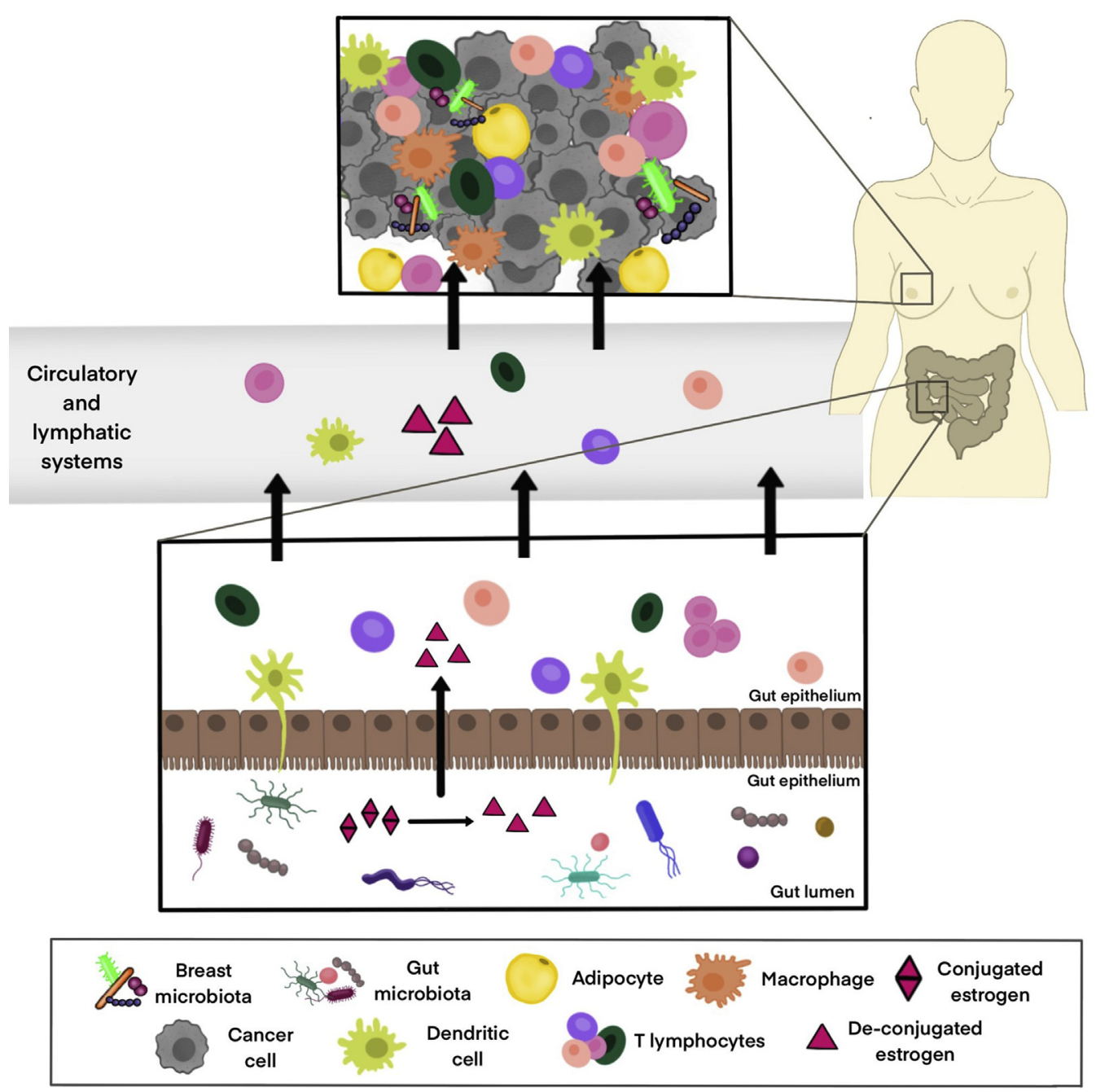

Figure 1 Interaction mechanisms between the gut and the breast. A connection between the gut and the breast has been demonstrated in human and mouse studies. The gut microbiota composition interacts with the host immune system and subsequently influences systemic immunity and the local immune environment in the breast. Furthermore, the gut microbiota has the capacity to influence systemic availability of estrogen through enterohepatic recycling of estrogen, because certain bacteria contain the enzyme beta-glucuronidase.

chemotherapeutics through biotransformation in both in vitro and in vivo cancer models. ${ }^{44}$ In this study, E. coli increased in vitro cytotoxicity of tegafur, fludarabine de phosphate, 5-fluorcytosine, 6-mercaptopurine-2'-deoxyriboside, AQ4N, and CB1954, and decreased cytotoxicity of cladribine, vidarabine, gemicitabine, doxorubicin, daunorubicin, etoposide phosphate, mitoxantrone, $\beta$-lapachone, and menadione. In vitro findings were confirmed in a CT26 murine colon carcinoma model. Intratumoral growth of $E$. coli, together with gemicitabine administration, resulted in increased tumor volume and reduced survival compared with a control group with only gemicitabine administered. ${ }^{44}$

To confirm that bacteria determine effectiveness of anticancer therapy, a pancreatic cancer study was sued to demonstrate reduction in gemcitabine concentration due to the presence of intratumoral Gammaproteobacteria, and increased chemotherapeutic sensitivity when treated with antibiotics. ${ }^{45}$ Proteobacteria are abundant in pancreatic cancer tissue, and when transferred to a colon cancer mouse model, these bacteria were shown to mediate gemcitabine resistance by metabolizing and inactivating the drug via the long form of bacterial enzyme cytidine deaminase $\left(\mathrm{CDD}_{\mathrm{L}}\right){ }^{45}$ Chemotherapeutics can also induce changes in intratumoral microbiota composition, because neoadjuvant chemotherapy reduced bacterial diversity in breast tumor tissue. ${ }^{46}$

Current immunotherapeutic strategies aim to block coinhibitory molecules in the TME, in order to reduce immunosuppression found in cancer. Immune checkpoint inhibitors, such as programed cell death 1 (PD-1) and cytotoxic T lymphocyte antigen 4 (CTLA-4) blocking antibodies, function by preventing T-cell inhibition. ${ }^{47}$ However, the clinical benefit of immune checkpoint inhibitors in breast cancer is not as effective as in other cancer types. ${ }^{48}$ To enhance immunotherapeutic efficacy, it is needed to better understand the mechanisms underlying immunotherapy resistance. The TME is a promising target to improve responsiveness to immunotherapy, which can be achieved by modulating protumor inflammation. ${ }^{25}$ The influence of gut microbiota on immunotherapeutic efficacy has been 


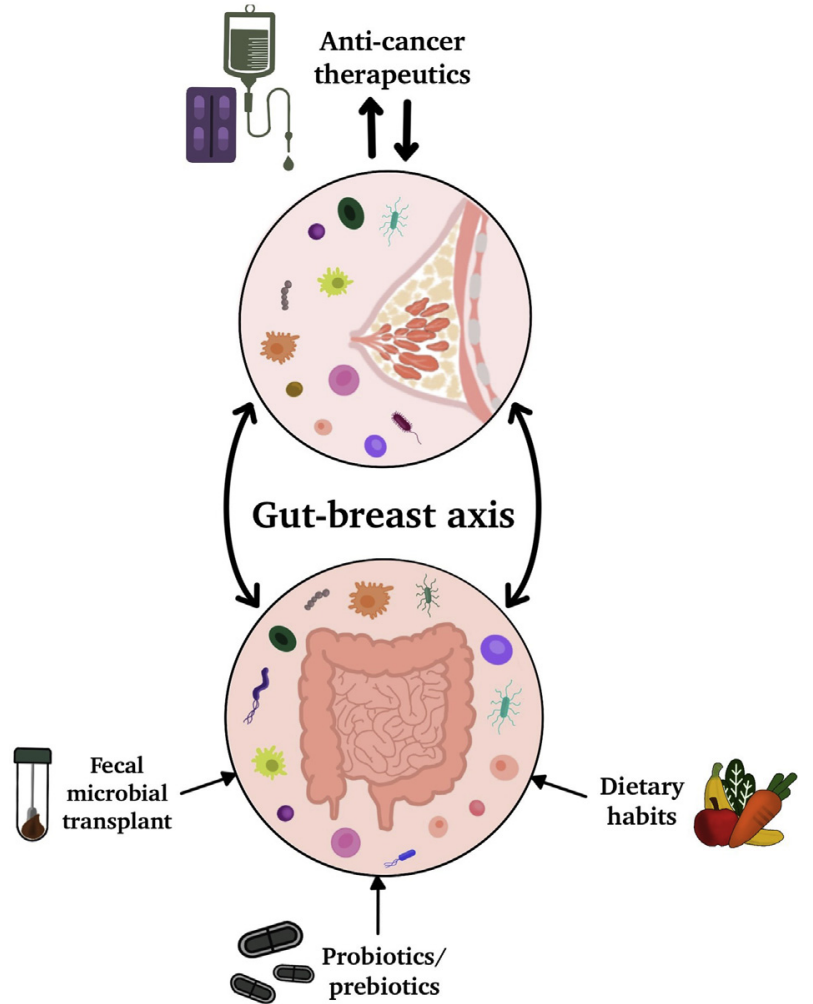

Figure 2 Proposed strategies to influence the gut-breast axis. Breast cancer is characterized by a unique microbiota and immune composition. Though little is known about manipulating these compositions in the breast, alteration of the gut microbiota composition might influence the breast tumor microenvironment as well. Strategies to positively alter gut microbiota comprise healthy dietary habits, pre- or probiotics, or more rigorously, fecal microbiota transplantation. Moreover, certain bacterial species potentially have the capacity to modulate anticancer agents by bacterial enzymatic activity.

described previously. ${ }^{48-50}$ However, it remains to be established whether intratumoral breast microbiota also influence the functioning of immunotherapeutics. This is a reasonable assumption, because activation of TLRs by bacterial products stimulate maturation and priming of immune cells.

\section{Gut-Breast Microbiota Axis}

Other than the direct effects of organ-specific microbiota on local tissue, the gut microbiota possibly affect breast cancer development through several mechanisms. ${ }^{11}$ Disruption of gut microbiota homeostasis, characterized by low gut microbial diversity and less beneficial bacteria, is associated with breast cancer. ${ }^{51}$ In addition, antibiotic treatment, which is known to disrupt gut microbiota homeostasis, is associated with increased breast cancer risk. ${ }^{52,53}$ Furthermore, established risk factors for breast cancer, such as obesity and alcohol consumption, are associated with dysbiosis of the intestinal microbiota. $^{54,55}$

The breast parenchyma can be influenced by the gut microbiota through different mechanisms, including via enterohepatic recycling of estrogens and bile acids, and microbial interaction with the innate and adaptive immune system.

\section{Estrogen and Bile Acids}

Estrogens are normally conjugated in the liver and delivered into the gut via bile excretion. ${ }^{56}$ In the gut reside bacteria with beta-glucuronidase enzymatic activity, capable of deconjugating conjugated estrogen. Deconjugated estrogen is reabsorbed into the circulation, resulting in systemically increased estrogen exposure and thereby increasing breast cancer risk. ${ }^{57}$

A main metabolic feature of intestinal microbes is bile acid conversion. Bile acids are soluble amphipathic molecules derived from cholesterol in the liver. ${ }^{58,59}$ Microbiota that reside in the intestinal lumen have the capacity to convert primary bile acids into secondary bile acids by the process of deconjugation and $7 \alpha$-dehydroxylation. ${ }^{58}$ Certain specific bile acids are functionally similar to hormones, due to their capacity to alter metabolic pathways in distant organ tissues by activating several receptors, including farnesoid $\mathrm{X}$ receptor (FXR), pregnane $\mathrm{X}$ receptor (PXR), vitamin $\mathrm{D}$ receptor (VDR), and Takeda G-protein-coupled receptor 5 (TGR5). ${ }^{58}$ The farnesoid $\mathrm{X}$ receptor has been detected in invasive breast carcinoma. ${ }^{60}$ Bile acids were found to be accumulated in breast tumors and were associated with antiproliferative effects and improved patient prognosis. ${ }^{61}$ Another study evaluated the effects in breast cancer of a separate bile acid. Lithocholic acid decreased breast cancer cell proliferation by oxidative stress induction and improved antitumor immunity by increasing tumor-infiltrating lymphocyte count in the breast. ${ }^{62}$

\section{Shaping Systemic Immunity}

The intestinal microbiota shapes the immune system. Gut dysbiosis modulates immune functioning, which might contribute to carcinogenesis. ${ }^{63,64}$ Various experimental mouse models exist, demonstrating carcinogenic regulation by gut microbes via interaction with the immune system. In mice, commensal dysbiosis of the gut, induced by oral antibiotics, significantly increases the number of myeloid cells present in normal adjacent breast gland tissue at both early and advanced stages of breast tumor progression. ${ }^{65}$ Moreover, these infiltrated myeloid cells exhibit high expressions of inflammatory mediators arginase-1 and IL-6. Myeloid recruitment into breast tissue is explained by corresponding increases in myeloid chemoattractants, namely CXCL10 and CCL2, which were up-regulated in dysbiotic mice compared with nondysbiotic mice. ${ }^{65}$

Neutrophils, members of the innate immune system, have been identified to mediate between the gut and extraintestinal organs. A specific bacterium, Helicobacter hepaticus, residing in the gut was shown to affect distant neoplastic progressions in breast tissue, in which neutrophils played a tumorigenic role. ${ }^{66}$ Mice with a predisposition for breast 
cancer underwent accelerated cancer progression when injected with $H$. hepaticus, compared with noninfected mice. However, mice systemically depleted of neutrophils showed only preneoplastic and early neoplastic lesions in the breast tissue, thus inhibiting carcinogenesis.

These findings indicate that the gut microbiota has the capacity to affect immune cell expression in breast tissue as well. In breast cancer patients, higher gut microbiota diversity is associated with increased tumor-infiltrating lymphocyte expression in breast tissue. ${ }^{67}$ A summary of breast microbiota interactions is illustrated in Figure 1.

\section{Translational Gaps - the Future of Using Microbiota to Fight Cancer}

Microbiota comprise a promising field of research, in which the breast microbiota can be used as biomarker to establish disease characteristics and subsequently used as a therapeutic target. Accumulated evidence confirms the presence of a unique microbial community in the breast. However, small sample sizes, interindividual heterogeneity of the microbiota, variances in methodological approaches (DNA extraction kit, target hypervariable region selection for sequencing, tissue extraction and storage), and patient characteristics (demography, dietary habits, menopausal status, breast cancer subtypes) limit comparability of results. Furthermore, the observational design of most studies only provides associative, but not causal, evidence for the relationship between microbial dysbiosis and breast carcinogenesis. Moreover, because tumor samples contain a low bacterial biomass, contamination can contribute to inaccurate findings. A major challenge in this field will be making the shift from descriptive analysis to functional metagenomics and metabolomics, in order to outline the functional roles of bacteria present in the breast and its interaction with the internal environment. Furthermore, rather than holding a single pathogen responsible for cancer progression, the accumulative effects of an entire microbial community are more likely to determine disease processes.

\section{The Breast Microbiota as a Biomarker for Cancer}

The breast microbiota could be used as a biomarker in several ways: i) pretreatment, to determine the molecular characteristics of the cancer, so that response or resistance to therapeutics can be predicted; ii) during treatment, enabling the adjustment of the therapy when unresponsive; and iii) during tumor progression, to elucidate the achieved resistance to therapeutics. ${ }^{68}$ Using microbiota as a pretreatment biomarker would provide most value to oncologists, because microbiota analysis would offer additional information on tumor aggressiveness and tumor sensitivity to anticancer therapeutics, after which, treatment type and regimen could be adjusted accordingly. Moreover, as per current protocols in breast cancer diagnosis, tissue specimens have already been obtained prior to treatment, placing no additional burden on patients.

To bring a biomarker to the clinic, five phases have been outlined. ${ }^{69}$ These include preclinical studies, clinical assay development, retrospective studies, prospective studies, and control studies. Currently, research regarding the breast microbiota is still in the preclinical, exploratory phase, because most studies have focused on identifying characteristics that are unique to breast tumor tissue, by comparing the microbiota of breast tumor tissue to healthy tissue.

Even though the breast microbiome exhibits great potential as a prognostic and predictive biomarker, further investigations are still required to consider the breast microbiome as a biomarker for prognosis or therapeutic response. First, more participants should be included in future studies, taking clinicopathological variability into account. Furthermore, by performing prospective studies, the prognostic value of pretreatment breast microbiota composition can be evaluated. Second, confounding factors should be taken into consideration, including menopausal status, age, ethnicity, body mass index, and lifestyle-related factors, such as alcohol consumption and dietary habits. Lastly, microbiota compositions should be identified that are able to predict efficacy and resistance to anticancer therapeutics, by comparing microbial composition of patients with differences in tumor progression and between responders and nonresponders. In order to obtain in-depth mechanistic insight into the relationship between breast cancer microbiota and anticancer agents, the use of animal models will be required.

\section{Modulating Breast Microbiota}

No studies have been conducted yet on how the breast microbiota composition could be manipulated. However, because the gut microbiota is able to affect the breast through several mechanisms, discussed above, the gut microbiota could be targeted. Beta-glucuronidase activity and gut-derived metabolites can be modulated by diet. ${ }^{56}$ Diets high in fat were found to increase betaglucuronidase activity in gut bacteria and diets high in fiber reduced this activity. Other factors that are known to elevate estrogen levels in the circulation are alcohol ingestion and adiposity. ${ }^{70} \mathrm{~A}$ more rigorous approach to manipulate gut microbiota composition is by the method of fecal microbiota transplantation. ${ }^{71}$ Another strategy encompasses the intake of pro- or prebiotics. ${ }^{72}$ However, more research is needed to understand how gut microbiota interacts with microbiota residing in the breast, and other breast microbial targeting possibilities need to be explored. In Figure 2, the proposed strategies to influence the gut-breast axis are summarized.

\section{Microbiota Investigation Techniques}

It remains to be investigated which intratumoral bacteria in the breast modulate anticancer agents, in order to identify 
possible targets for breast cancer therapeutics. Alongside this, its interactions with the immune system deserve attention as well. This can be best done by combining metagenomics and metabolomics sequencing with preclinical models, such as gnotobiotic mice and patient-derived tumor xenografts (PDTXs). ${ }^{73}$ Gnotobiotic mice refers to animals with known microbiota composition, either germfree mice or ex-germ-free animals. ${ }^{74}$ PDTXs exist of immunodeficient mice to which patient-derived material is transferred. ${ }^{75}$ Another possible preclinical model that can be combined with sequencing is the in vitro three-dimensional model termed organoid. ${ }^{75}$ Transferring breast cancer microbiota to these models will contribute to the understanding of patient-specific tumorigenic and therapeutic modulatory potential of intratumoral bacteria. Identifying which microbial composition favors a positive response to anticancer therapy is important to increase therapeutic effectiveness. $^{73}$

\section{Summary}

Breast microbiota holds many possibilities to reveal more insight into the pathophysiology of breast cancer. Using the breast microbiome as a marker to predict breast cancer prognosis and therapeutic response holds promise. Targeting microbiota could be used to improve therapeutic efficiency and reduce related toxicity. Before breast microbiota analysis can be implemented, major knowledge gaps need to be considered. There is limited understanding of the contribution of breast microbiota to cancer development and treatment response. Because indications exist that breast microbiota components interact with the gut microbiota and the immune system, these need to be explored in parallel.

\section{References}

1. Bland KI, Copeland EM, Klimberg VS, Gradishar WJ (Eds): The Breast E-Book: Comprehensive Management of Benign and Malignant Diseases. ed 5. Philadelphia, PA: Elsevier Health Sciences, 2017

2. Siegel RL, Miller KD, Jemal A: Cancer statistics, 2020. CA Cancer J Clin 2020, 70:7-30

3. Sørlie T: Molecular portraits of breast cancer: tumour subtypes as distinct disease entities. Eur J Cancer 2004, 40:2667-2675

4. Tsang JYS, Tse GM: Molecular classification of breast cancer. Adv Anat Pathol 2020, 27:27-35

5. Clarke R, Tyson JJ, Dixon JM: Endocrine resistance in breast canceran overview and update. Mol Cell Endocrinol 2015, 418 Pt 3: $220-234$

6. Chen F, Zhuang X, Lin L, Yu P, Wang Y, Shi Y, Hu G, Sun Y: New horizons in tumor microenvironment biology: challenges and opportunities. BMC Med 2015, 13:45

7. Dickson RP, Erb-Downward JR, Martinez FJ, Huffnagle GB: The microbiome and the respiratory tract. Annu Rev Physiol 2016, 78: 481-504

8. Xuan C, Shamonki JM, Chung A, Dinome ML, Chung M, Sieling PA, Lee DJ: Microbial dysbiosis is associated with human breast cancer. PLoS One 2014, 9:e83744
9. Thomas RM, Jobin C: Microbiota in pancreatic health and disease: the next frontier in microbiome research. Nat Rev Gastroenterol Hepatol 2019, 17:53-64

10. Metzker ML: Sequencing technologies - the next generation. Nat Rev Genet 2010, 11:31-46

11. McQuade JL, Daniel CR, Helmink BA, Wargo JA: Modulating the microbiome to improve therapeutic response in cancer. Lancet Oncol 2019, 20:e77-e91

12. Hieken TJ, Chen J, Hoskin TL, Walther-Antonio M, Johnson S, Ramaker S, Xiao J, Radisky DC, Knutson KL, Kalari KR, Yao JZ, Baddour LM, Chia N, Degnim AC: The microbiome of aseptically collected human breast tissue in benign and malignant disease. Sci Rep 2016, 6:30751

13. Nejman D, Livyatan I, Fuks G, Gavert N, Zwang Y, Geller LT, et al: The human tumor microbiome is composed of tumor type-specific intracellular bacteria. Science 2020, 368:973-980

14. Thompson KJ, Ingle JN, Tang $\mathrm{X}$, Chia N, Jeraldo PR, WaltherAntonio MR, Kandimalla KK, Johnson S, Yao JZ, Harrington SC, Suman VJ, Wang L, Weinshilboum RL, Boughey JC, Kocher JP, Nelson H, Goetz MP, Kalari KR: A comprehensive analysis of breast cancer microbiota and host gene expression. PLoS One 2017, 12: e0188873

15. Smith A, Pierre JF, Makowski L, Tolley E, Lyn-Cook B, Lu L, Vidal G, Starlard-Davenport A: Distinct microbial communities that differ by race, stage, or breast-tumor subtype in breast tissues of non-Hispanic Black and non-Hispanic White women. Sci Rep 2019, 9:11940

16. Wang H, Altemus J, Niazi F, Green H, Calhoun BC, Sturgis C, Grobmyer SR, Eng C: Breast tissue, oral and urinary microbiomes in breast cancer. Oncotarget 2017, 8:88122-88138

17. Costantini L, Magno S, Albanese D, Donati C, Molinari R, Filippone A, Masetti R, Merendino N: Characterization of human breast tissue microbiota from core needle biopsies through the analysis of multi hypervariable 16S-rRNA gene regions. Sci Rep 2018, 8:16893

18. Urbaniak C, Gloor GB, Brackstone M, Scott L, Tangney M, Reid G: The microbiota of breast tissue and its association with breast cancer. Appl Environ Microbiol 2016, 82:5039-5048

19. Pleguezuelos-Manzano C, Puschhof J, Rosendahl Huber A, van Hoeck A, Wood HM, Nomburg J, Gurjao C, Manders F, Dalmasso G, Stege PB, Paganelli FL, Geurts MH, Beumer J, Mizutani T, Miao Y, van der Linden R, van der Elst S; Genomics England Research Consortium, Garcia KC, Top J, Willems RJL, Giannakis M, Bonnet R, Quirke P, Meyerson M, Cuppen E, van Boxtel R, Clevers H: Mutational signature in colorectal cancer caused by genotoxic pks(+) E. coli. Nature 2020, 580:269-273

20. Meng S, Chen B, Yang J, Wang J, Zhu D, Meng Q, Zhang L Study of microbiomes in aseptically collected samples of human breast tissue using needle biopsy and the potential role of in situ tissue microbiomes for promoting malignancy. Front Oncol 2018, 8:318

21. Banerjee S, Wei Z, Tan F, Peck KN, Shih N, Feldman M, Rebbeck TR, Alwine JC, Robertson ES: Distinct microbiological signatures associated with triple negative breast cancer. Sci Rep 2015, 5:15162

22. Banerjee S, Tian T, Wei Z, Shih N, Feldman MD, Peck KN, DeMichele AM, Alwine JC, Robertson ES: Distinct microbial signatures associated with different breast cancer types. Front Microbiol 2018, 9:951

23. Dunn GP, Old LJ, Schreiber RD: The immunobiology of cancer immunosurveillance and immunoediting. Immunity 2004, 21: $137-148$

24. Murciano-Goroff YR, Warner AB, Wolchok JD: The future of cancer immunotherapy: microenvironment-targeting combinations. Cell Res 2020, 30:507-519

25. Beatty GL, Gladney WL: Immune escape mechanisms as a guide for cancer immunotherapy. Clin Cancer Res 2015, 21:687-692

26. Gatti-Mays ME, Balko JM, Gameiro SR, Bear HD, Prabhakaran S, Fukui J, Disis ML, Nanda R, Gulley JL, Kalinsky K, Abdul Sater H, Sparano JA, Cescon D, Page DB, McArthur H, Adams S, 
Mittendorf EA: If we build it they will come: targeting the immune response to breast cancer. NPJ Breast Cancer 2019, 5:37

27. Wang M, Zhang C, Song Y, Wang Z, Wang Y, Luo F, Xu Y, Zhao Y, Wu Z, Xu Y: Mechanism of immune evasion in breast cancer. Onco Targets Ther 2017, 10:1561-1573

28. Ali HR, Provenzano E, Dawson S-J, Blows FM, Liu B, Shah M, Earl HM, Poole CJ, Hiller L, Dunn JA, Bowden SJ, Twelves C, Bartlett JMS, Mahmoud SMA, Rakha E, Ellis IO, Liu S, Gao D, Nielsen TO, Pharoah PDP, Caldas C: Association between CD8+ T-cell infiltration and breast cancer survival in 12,439 patients. Ann Oncol 2014, 25:1536-1543

29. Plitas G, Konopacki C, Wu K, Bos PD, Morrow M, Putintseva EV, Chudakov DM, Rudensky AY: Regulatory T cells exhibit distinct features in human breast cancer. Immunity 2016, 45:1122-1134

30. Safarzadeh E, Hashemzadeh S, Duijf PHG, Mansoori B, Khaze V, Mohammadi A, Kazemi T, Yousefi M, Asadi M, Mohammadi H, Babaie F, Baradaran B: Circulating myeloid-derived suppressor cells: an independent prognostic factor in patients with breast cancer. J Cell Physiol 2019, 234:3515-3525

31. Pinto ML, Rios E, Durães C, Ribeiro R, Machado JC, Mantovani A, Barbosa MA, Carneiro F, Oliveira MJ: The two faces of tumorassociated macrophages and their clinical significance in colorectal cancer. Front Immunol 2019, 10:1875

32. Solinas G, Germano G, Mantovani A, Allavena P: Tumor-associated macrophages (TAM) as major players of the cancer-related inflammation. J Leukoc Biol 2009, 86:1065-1073

33. Zhao X, Qu J, Sun Y, Wang J, Liu X, Wang F, Zhang H, Wang W, Ma X, Gao X, Zhang S: Prognostic significance of tumor-associated macrophages in breast cancer: a meta-analysis of the literature. Oncotarget 2017, 8:30576-30586

34. Negi S, Das DK, Pahari S, Nadeem S, Agrewala JN: Potential role of gut microbiota in induction and regulation of innate immune memory. Front Immunol 2019, 10:2441

35. Kovács T, Mikó E, Ujlaki G, Sári Z, Bai P: The microbiome as a component of the tumor microenvironment. Adv Exp Med Biol 2020, 1225:137-153

36. Dajon M, Iribarren K, Cremer I: Toll-like receptor stimulation in cancer: a pro- and anti-tumor double-edged sword. Immunobiology 2017, 222:89-100

37. Cai Z, Sanchez A, Shi Z, Zhang T, Liu M, Zhang D: Activation of Toll-like receptor 5 on breast cancer cells by flagellin suppresses cell proliferation and tumor growth. Cancer Res 2011, 71:2466-2475

38. Yang H, Wang B, Wang T, Xu L, He C, Wen H, Yan J, Su H, Zhu X: Toll-like receptor 4 prompts human breast cancer cells invasiveness via lipopolysaccharide stimulation and is overexpressed in patients with lymph node metastasis. PLoS One 2014, 9:e109980

39. Riquelme E, Zhang Y, Zhang L, Montiel M, Zoltan M, Dong W, Quesada P, Sahin I, Chandra V, San Lucas A: Tumor microbiome diversity and composition influence pancreatic cancer outcomes. Cell 2019, 178:795-806.e12

40. Pushalkar S, Hundeyin M, Daley D, Zambirinis CP, Kurz E, Mishra A, Mohan N, Aykut B, Usyk M, Torres LE, Werba G, Zhang K, Guo Y, Li Q, Akkad N, Lall S, Wadowski B, Gutierrez J, Kochen Rossi JA, Herzog JW, Diskin B, Torres-Hernandez A, Leinwand J, Wang W, Taunk PS, Savadkar S, Janal M, Saxena A, Li X, Cohen D, Sartor RB, Saxena D, Miller G: The pancreatic cancer microbiome promotes oncogenesis by induction of innate and adaptive immune suppression. Cancer Discov 2018, 8:403-416

41. Le Noci V, Guglielmetti S, Arioli S, Camisaschi C, Bianchi F, Sommariva M, Storti C, Triulzi T, Castelli C, Balsari A: Modulation of pulmonary microbiota by antibiotic or probiotic aerosol therapy: a strategy to promote immunosurveillance against lung metastases. Cell Rep 2018, 24:3528-3538

42. Vasan N, Baselga J, Hyman DM: A view on drug resistance in cancer. Nature 2019, 575:299-309

43. Wallace BD, Wang H, Lane KT, Scott JE, Orans J, Koo JS, Venkatesh M, Jobin C, Yeh L-A, Mani S: Alleviating cancer drug toxicity by inhibiting a bacterial enzyme. Science 2010, 330: $831-835$

44. Lehouritis P, Cummins J, Stanton M, Murphy CT, McCarthy FO, Reid G, Urbaniak C, Byrne WL, Tangney M: Local bacteria affect the efficacy of chemotherapeutic drugs. Sci Rep 2015, 5:14554

45. Geller LT, Barzily-Rokni M, Danino T, Jonas OH, Shental N, Nejman D, et al: Potential role of intratumor bacteria in mediating tumor resistance to the chemotherapeutic drug gemcitabine. Science 2017, 357:1156-1160

46. Chiba A, Bawaneh A, Velazquez C, Clear KYJ, Wilson AS, HowardMcNatt M, Levine EA, Levi-Polyachenko N, Yates-Alston SA, Diggle SP, Soto-Pantoja DR, Cook KL: Neoadjuvant chemotherapy shifts breast tumor microbiota populations to regulate drug responsiveness and the development of metastasis. Mol Cancer Res 2020, 18:130-139

47. Waldman AD, Fritz JM, Lenardo MJ: A guide to cancer immunotherapy: from $\mathrm{T}$ cell basic science to clinical practice. Nat Rev Immunol 2020, 20:651-668

48. Seto T, Sam D, Pan M: Mechanisms of primary and secondary resistance to immune checkpoint inhibitors in cancer. Med Sci (Basel) 2019, 7:14

49. Routy B, Le Chatelier E, Derosa L, Duong CPM, Alou MT, Daillère R, et al: Gut microbiome influences efficacy of PD-1-based immunotherapy against epithelial tumors. Science 2018, 359: 91-97

50. Guven DC, Aktas BY, Simsek C, Aksoy S: Gut microbiota and cancer immunotherapy: prognostic and therapeutic implications. Future Oncol 2020, 16:497-506

51. Goedert JJ, Jones G, Hua X, Xu X, Yu G, Flores R, Falk RT, Gail MH, Shi J, Ravel J, Feigelson HS: Investigation of the association between the fecal microbiota and breast cancer in postmenopausal women: a population-based case-control pilot study. J Natl Cancer Inst 2015, 107:djv147

52. Velicer CM, Heckbert SR, Lampe JW, Potter JD, Robertson CA, Taplin SH: Antibiotic use in relation to the risk of breast cancer. JAMA 2004, 291:827-835

53. Kirkup BM, McKee A, Makin KA, Paveley J, Caim S, AlconGiner C, Leclaire C, Dalby M, Le Gall G, Andrusaite A, Kreuzaler P, Ghanate A, Driscoll P, MacRae J, Calvani E, Milling SWF, Yuneva M, Weilbaecher KN, Korcsmáros T, Hall LJ, Robinson SD: Perturbation of the gut microbiota by antibiotics results in accelerated breast tumour growth and metabolic dysregulation. bioRxiv 2019 [Epub] doi: 10.1101/553602

54. Le Chatelier E, Nielsen T, Qin J, Prifti E, Hildebrand F, Falony G, et al: Richness of human gut microbiome correlates with metabolic markers. Nature 2013, 500:541-546

55. Engen PA, Green SJ, Voigt RM, Forsyth CB, Keshavarzian A: The gastrointestinal microbiome: alcohol effects on the composition of intestinal microbiota. Alcohol Res 2015, 37:223-236

56. Kwa M, Plottel CS, Blaser MJ, Adams S: The intestinal microbiome and estrogen receptor-positive female breast cancer. J Natl Cancer Inst 2016, 108:djw029

57. Parida S, Sharma D: The microbiome-estrogen connection and breast cancer risk. Cells 2019, 8:1642

58. de Aguiar Vallim TQ, Tarling EJ, Edwards PA: Pleiotropic roles of bile acids in metabolism. Cell Metab 2013, 17:657-669

59. Lefebvre P, Cariou B, Lien F, Kuipers F, Staels B: Role of bile acids and bile acid receptors in metabolic regulation. Physiol Rev 2009, 89: 147-191

60. Swales KE, Korbonits M, Carpenter R, Walsh DT, Warner TD, Bishop-Bailey D: The farnesoid X receptor is expressed in breast cancer and regulates apoptosis and aromatase expression. Cancer Res 2006, 66:10120-10126

61. Tang W, Putluri V, Ambati CR, Dorsey TH, Putluri N, Ambs S: Liver- and microbiome-derived bile acids accumulate in human breast tumors and inhibit growth and improve patient survival. Clin Cancer Res 2019, 25:5972-5983 
62. Mikó E, Vida A, Kovács T, Ujlaki G, Trencsényi G, Márton J, Sári Z, Kovács P, Boratkó A, Hujber Z, Csonka T, Antal-Szalmás P, Watanabe M, Gombos I, Csoka B, Kiss B, Vígh L, Szabó J, Méhes G, Sebestyén A, Goedert JJ, Bai P: Lithocholic acid, a bacterial metabolite reduces breast cancer cell proliferation and aggressiveness. Biochim Biophys Acta Bioenerg 2018, 1859:958-974

63. Buchta Rosean CM, Rutkowski MR: The influence of the commensal microbiota on distal tumor-promoting inflammation. Semin Immunol 2017, 32:62-73

64. Vivarelli S, Salemi R, Candido S, Falzone L, Santagati M, Stefani S, Torino F, Banna GL, Tonini G, Libra M: Gut microbiota and cancer: from pathogenesis to therapy. Cancers (Basel) 2019, 11:38

65. Buchta Rosean C, Bostic RR, Ferey JCM, Feng TY, Azar FN, Tung KS, Dozmorov MG, Smirnova E, Bos PD, Rutkowski MR: Preexisting commensal dysbiosis is a host-intrinsic regulator of tissue inflammation and tumor cell dissemination in hormone receptorpositive breast cancer. Cancer Res 2019, 79:3662-3675

66. Lakritz JR, Poutahidis T, Mirabal S, Varian BJ, Levkovich T, Ibrahim YM, Ward JM, Teng EC, Fisher B, Parry N, Lesage S, Alberg N, Gourishetti S, Fox JG, Ge Z, Erdman SE: Gut bacteria require neutrophils to promote mammary tumorigenesis. Oncotarget 2015, 6:9387-9396

67. Shi J, Geng C, Sang M, Gao W, Li S, Yang S, Li Z: Effect of gastrointestinal microbiome and its diversity on the expression of tumor-infiltrating lymphocytes in breast cancer. Oncol Lett 2019, 17: $5050-5056$

68. Olson EM, Lin NU, Krop IE, Winer EP: The ethical use of mandatory research biopsies. Nat Rev Clin Oncol 2011, 8:620-625

69. Pepe MS, Etzioni R, Feng Z, Potter JD, Thompson ML, Thornquist M, Winget M, Yasui Y: Phases of biomarker development for early detection of cancer. J Natl Cancer Inst 2001, 93:1054-1061

70. Dorgan JF, Baer DJ, Albert PS, Judd JT, Brown ED, Corle DK, Campbell WS, Hartman TJ, Tejpar AA, Clevidence BA, Giffen CA, Chandler DW, Stanczyk FZ, Taylor PR: Serum hormones and the alcohol-breast cancer association in postmenopausal women. J Natl Cancer Inst 2001, 93:710-715

71. Chen D, Wu J, Jin D, Wang B, Cao H: Fecal microbiota transplantation in cancer management: current status and perspectives. Int J Cancer 2019, 145:2021-2031

72. Górska A, Przystupski D, Niemczura MJ, Kulbacka J: Probiotic bacteria: a promising tool in cancer prevention and therapy. Curr Microbiol 2019, 76:939-949

73. Elinav E, Garrett WS, Trinchieri G, Wargo J: The cancer microbiome. Nat Rev Cancer 2019, 19:371-376

74. Fessler J, Matson V, Gajewski TF: Exploring the emerging role of the microbiome in cancer immunotherapy. J Immunother Cancer 2019, 7:108

75. Drost J, Clevers H: Organoids in cancer research. Nat Rev Cancer 2018, 18:407-418 